\title{
DÜBLIN
}

Technological University Dublin

ARROW@TU Dublin

Articles

School of Marketing

2018

\section{Beauty bloggers and YouTubers as a community of practice}

\author{
Valerie Gannon \\ Technological University Dublin, valerie.gannon@TUDublin.ie \\ Andrea Prothero \\ University College Dublin
}

Follow this and additional works at: https://arrow.tudublin.ie/buschmarart

Part of the Marketing Commons

\section{Recommended Citation}

Valerie Gannon \& Andrea Prothero (2018) Beauty bloggers and YouTubers as a community of practice, Journal of Marketing Management, 34:7-8, 592-619, DOI: 10.1080/0267257X.2018.1482941

This Article is brought to you for free and open access by the School of Marketing at ARROW@TU Dublin. It has been accepted for inclusion in Articles by an authorized administrator of ARROW@TU Dublin. For more information, please contact arrow.admin@tudublin.ie, aisling.coyne@tudublin.ie, gerard.connolly@tudublin.ie.

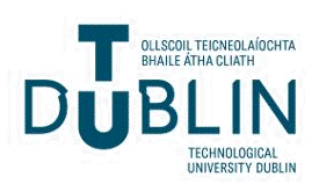




\section{Beauty bloggers and YouTubers as a community of practice}

\section{Valerie Gannon \& Andrea Prothero}

To cite this article: Valerie Gannon \& Andrea Prothero (2018) Beauty bloggers and YouTubers as a community of practice, Journal of Marketing Management, 34:7-8, 592-619, DOI:

10.1080/0267257X.2018.1482941

To link to this article: https://doi.org/10.1080/0267257X.2018.1482941

\section{Published online: 19 Jul 2018.}

Submit your article to this journal ๘

Џll Article views: 4755

Q View related articles $\asymp$

View Crossmark data \lceil

4 Citing articles: 7 View citing articles 


\title{
Beauty bloggers and YouTubers as a community of practice
}

\author{
Valerie Gannon ${ }^{\mathrm{a}}$ and Andrea Prothero ${ }^{\mathrm{b}}$ \\ ${ }^{a}$ College of Business, Dublin Institute of Technology, Dublin, Ireland; ' $Q$ Quinn School of Business, University \\ College Dublin, Dublin, Ireland
}

\begin{abstract}
Much consumption-related activity online is outside of what is understood traditionally as community and is via user-generated content (UGC), of which blogs and YouTube channels in particular dominate in the beauty sphere. Community of practice (CoP) theory from social learning and organisation studies offers an alternative way to understand these consumption-based UGC practices. This study combines data from 25 interviews with bloggers and YouTubers and their blog posts and videos. Among these UGC creators we find mutual engagement, shared repertoires and joint enterprise. This paper theorises consumption-based UGC creators as a CoP and contributes insights for mangers as to how to engage with them as practitioners and learners.
\end{abstract}

\section{ARTICLE HISTORY}

Received 23 April 2017

Accepted 22 April 2018

\section{KEYWORDS}

Social networks; new media; consumer culture; identity; netnography; internet research; community of practice; user-generated content

\section{Introduction}

The concept of community of practice (CoP) has been widely theorised and applied in organisation studies (Nicolini, 2012). CoP has been defined as 'groups of people who share a concern, a set of problems, or a passion about a topic, and who deepen their knowledge and expertise in this area by interacting on an ongoing basis' (Wenger, McDermott, \& Snyder, 2002, p. 4). CoP provides an alternative but little used perspective on consumption-based social connection and learning. Groups and their practices around consumption activities have long been of interest to consumer researchers (Cova \& Cova, 2002; Muñiz \& O'Guinn, 2001) and have usually been researched either as subcultures (Schouten \& McAlexander, 1995), brand communities (Muñiz \& O'Guinn, 2001), consumer tribes (Cova, Kozinets, \& Shankar, 2007) or virtual communities (Kozinets, 1999). However Goulding, Shankar, and Canniford (2013) show how CoP can be used to understand offline consumption-based groups and their practices.

Contemporary consumption-related activity has exploded online outside what has traditionally been defined as online community and in the form of user-generated content (UGC) (Edwards, 2011; Fader \& Winer, 2012). Much UGC is shared on blogs and YouTube channels, and because this involves social connection researchers have considered whether blogger and YouTuber networks constitute communities. While a recent study does not find community in fashion blogging, this is because it looks for community vertically between bloggers and their readers rather than horizontally

CONTACT Valerie Gannon valerie.gannon@dit.ie College of Business, Dublin Institute of Technology, Dublin, Ireland

(c) 2018 Westburn Publishers Ltd. 
between bloggers (McQuarrie, Miller, \& Phillips, 2013). Most researchers who look at interactions between UGC creators horizontally find community (Kozinets, de Valck, Wojnicki, \& Wilner, 2010; Simonsen, 2013). In addition some consideration has been given to conceptualising UGC creation as practices (Downes, 2007; Light, Griffiths, \& Lincoln, 2012; Schau, Muñiz, \& Arnould, 2009; Sorensen \& Mara, 2014). However, blogs and YouTube channels have not previously been theorised as a CoP.

From a managerial perspective there is significant interest in the growth of both blogs and YouTube videos on consumption topics generally, and on beauty specifically (WARC, 2011), a category that is growing exponentially (Pixability, 2015), and creating huge market impact (Weinsweg, 2017). Given the impact of beauty UGC on the beauty market, there is keen managerial interest in understanding how best to leverage beauty bloggers and YouTubers (Hall, 2017; Pixability, 2015; Weinsweg, 2017) and a fuller understanding of their practices and the social connection between them would aid this. Goulding et al. (2013) have demonstrated that the learning in the CoP they study is of importance to managers. Here we ask whether UGC, in the form of blogs and YouTube, specifically in the beauty context, can be considered a CoP, and if so, how this is important to managers.

This paper will first discuss literature relating to CoP; second, literature considering social connection via blogs and YouTube channels is examined. Following from this a practice-based methodology for this study will then be outlined. Description of findings focusing on three core characteristics of CoP - mutual engagement, shared repertoires and joint enterprise - are outlined, and contributions to theory and practice focusing on consumption-based CoP are put forward.

\section{Community of practice}

CoPs are defined as groups of people linked by a concern, problems or a passion for a topic, and whose knowledge and expertise is deepened by mutual interaction (Wenger et al., 2002, p. 4). In a CoP, people are envisaged as connected by shared interests and expertise in social learning systems (Wenger, 2010). Conceptualisations of community, brand community and consumption community all share two broad elements: a 'sense of community' (McMillan \& Chavis, 1986), 'sense of virtual community' (Blanchard, Askay, \& Frear, 2010) or 'sense of belonging', along with 'shared social relationships and actions' (Thomas, Price, \& Schau, 2013, p. 1012). CoP is also envisaged as sharing an imagined community (Wenger, 2000, 2010). However, a CoP is conceptualised as involving two further broad structuring elements by which it is brought about: both a domain of knowledge, and practices understood as 'socially defined ways of doing things in (the) specific domain' (Wenger et al., 2002, p. 34). CoP draws on theories of community, practice, meaning, experience and identity to understand the learning that emerges around shared repertoires of practice (Wenger, 1998).

Wenger $(1998,2000)$ identifies that community is built via practice where there are three specific elements. First mutual engagement is required: interpersonal interaction, establishing norms and relationships (Wenger, 2000) and engaging in joint activities (Wenger, 1998); second, CoPs involve a shared repertoire of 'communal resources - language, routines, sensibilities, artifacts, tools, stories, styles, etc.' (p. 229); and third, CoPs are brought into being jointly where there is evidence of a 'negotiated enterprise' (p. 229): where the practices 
creating the community are in part indigenous or grass-roots (p. 229): and where there is mutual accountability in the sense of mutual referencing in relation to what matters, how to enact practices and how to talk about them.

Belonging to a CoP can take one of three different modes, according to Wenger (2000). The first mode is engagement: a mix of doing, talking, producing, helping or participating generally; the second mode is imagining a sense of community; and the third mode is alignment: the mutual process by which participants engage in ways that are broadly in keeping with general community practices (Wenger, 2000).

In CoP theory practitioners are envisaged as learning via participation in the practice (Wenger, 2010). In turn, via engagement with the practice and the community, practitioners are not alone learning, but potentially incrementally shaping the practice: learning, identity, participation, social connection and the practice itself are mutually inscribed (Nicolini, 2012; Wenger, 2010). Lave and Wenger (1991) describe the process of socialization into a practice 'legitimate peripheral participation' whereby an individual is learning the craft, as it were.

Determining the level of analysis for CoP is debated (Fuller, 2007; Hughes Jewson and Unwin, 2007). Fuller (2007) points out that both narrow and broad views of the boundaries of CoP have been put forward. Narrow views focus on CoP as a tight-knit group; broad views envision CoP as a Russian doll continuum of communities from the primary tight-knit group to the broadest levels of the practice, spanning layers of social relationships (Hughes et al., 2007). However Fuller (2007) points out that both approaches have tended to view CoP as a 'container' of context. Contrary to this, Nicolini $(2012$, p. 94) proposes 'the practice ... performs the community and not the other way around'. This study follows Nicolini (2012) in defining the unit of analysis as the practices, not the community. Furthermore we understand that those practices can be viewed in a particular situation or context, but may span multiple social layers, contexts or sites (Fuller, 2007). The boundaries of the community are therefore determined by the situated practice (Fuller, 2007; Nicolini, 2012).

Recent scholarship has identified three broad categories and phases of research in relation to consumption-based social connection (Canniford, 2011a, 2011b; Goulding et al., 2013; Thomas et al., 2013). The first can be dated from Schouten and McAlexander's (1995) study of new bikers and introduced the '"sub-cultural" consumer' (Goulding et al., 2002, p. 263); a second phase focused on communities built around individual brands (Muñiz \& O'Guinn, 2001); and a third phase and category identifies consumers as tribal, members of multiple consumption groupings, engaging in related behaviour that is playful, transient and entrepreneurial (Canniford, 2011a, 2011b; Goulding et al., 2013).

However, CoP offers an alternative approach to the study of consumption groupings. While it has largely been used to research and understand organisational and professional domains (Nicolini, 2012) both offline and online (Gunawardena et al., 2009; Wenger et al., 2002), CoP is situated within a broader stream of social theories relating to practices, generally now well established in consumption studies (Warde, 2014). In addition Schau et al. (2009) show how practices generally can be understood in online consumption communities. Goulding et al.'s (2013) study of clubbers demonstrates that CoP can be used to understand offline consumer groups. Goulding et al. (2013) suggest that understanding how consumer groupings form and learn is important from a 
managerial perspective, as it enables a better understanding of how they might be leveraged. Using Wenger's (1998) three modes of involvement with a CoP (engagement, imagination and alignment) they show how the night clubbers in their study engage in clubbing, see themselves as part of a broader clubbing community, and participate in clubbing activities in ways that are influenced and in line with how things are generally 'done' in that scene. In general they learn how to be competent as clubbers as they go along, and develop related rituals (Goulding et al., 2013).

Other studies, while not situated within consumption research streams per se, have demonstrated that groupings around recreational interests can be understood as a CoP: vis Waldron's $(2011,2013)$ study of old time and bluegrass banjo players and enthusiasts. Indeed Wenger et al. (2002) encourage theorising communities in consumer markets as CoPs, for example DIY enthusiasts 'connected by the practice of home improvement', or consumer groups 'organizing around topics such as travel, parenting, musical interests, and fitness activities' (p. 222).

Overall then CoP is a well-established framework in organisation studies (Nicolini, 2012), has been clearly demonstrated as a useful way of understanding consumption groupings in an offline context, and is encouraged as a way of understanding consumption-based groups (Wenger et al., 2002). Consumption-based groupings have been variously theorised as subcultures (Schouten \& McAlexander, 1995), brand communities (Muñiz \& O'Guinn, 2001), consumer tribes (Cova et al., 2007) or virtual communities (Kozinets, 1999). However, consumption groupings have been theorised as a CoP only for an offline context (Goulding et al., 2013). Therefore identifying whether an online consumption-based grouping can be understood as a CoP is of interest to managers who wish to leverage consumption-based groupings, and to theorists further researching consumption-based groups, communities of practice and virtual communities.

\section{Community online}

The term, and perhaps the first, virtual community, was identified by Rheingold, and emanated from an offline communitarian endeavour (Rheingold, 1993). In this phase of online community research debate often focused on whether early communitarian ideals were being upheld in Cyberspace and conceptualisations of virtual or online communities were often broad, embracing email or discussion lists, Usenet and MultiUser Domains, for example (Kollock \& Smith, 1999). As research on online community developed some researchers insisted on the necessity for a virtual settlement as a 'virtual common-public-space' where virtual community interactions could occur analogous to place-based community (Jones, 1997). However, Wellman, Boase, and Chen (2002) argue that network-based community has now supplanted place-based community, aided by the integration of social media into everyday life. Other authors argue that sense of community, not virtual place, important offline (McMillan \& Chavis, 1986), is also a key element of virtual community; they term online sense of community 'sense of virtual community' (Blanchard et al., 2010). Definitions of online or virtual community have varied but all include 'interaction around a shared interest online', mediated by technology and following protocols or norms (Porter, 2004). Muñiz and O'Guinn (2001) contributed to understanding communities online forming around brands and reiterate that a shared consciousness, along with shared practices relating to a brand, are key. 
Understandings of online community then have moved overtime from virtual places with communitarian ethos, to varieties of online togetherness (Bakardjieva, 2003), linked by networks and practices (Porter, 2004; Wellman et al., 2002).

In recent years, a new kind of online consumption-based activity has grown exponentially, in the form of UGC blog and YouTube material. This UGC is attracting considerable managerial interest focused on the potential for this material to influence consumer decision-making and purchases (Anderson, 2015; Johnson, 2015; Kozinets et al., 2010; WARC, 2011) particularly in the beauty and fashion arena (Dolbec \& Fischer, 2015; Kretz, 2012; Kretz \& de Valck, 2013; McQuarrie et al., 2013). As this UGC creator activity involves networked practices, many researchers have considered the nature of the social connection involved and whether or not it can be understood to produce community.

Many researchers have pointed out that blogs facilitate and encourage social connection via comment sections, direct-messaging (Blanchard, 2004; Lange, 2009) and blogrolls (Blanchard, 2004; Walker Rettberg, 2008), and sociability is experienced (Miller \& Shepherd, 2004) and rated 'essential' by bloggers themselves (boyd (sic), 2006, online). Likewise YouTube is structurally designed to encourage connectivity (Lindgren, 2012) 'through folksonomies, tags and links' (Simonsen, 2013, p. 61) and functions for sharing and social connection among gamers (Simonsen, 2013), graffiti artists (Light et al., 2012), live music fans (Lingel \& Naaman, 2012) and readers identifying as 'Book Tubers' (Sorensen \& Mara, 2014).

Furthermore, many researchers have proposed that bloggers and YouTubers can be understood as forming community (Burgess, 2007; Droge, Stanko, \& Pollitte, 2010; Kozinets et al., 2010; Uzunoğlu \& Kip, 2014; Walker Rettberg, 2008). On the other hand, McQuarrie et al.'s (2013) recent study of fashion blogs found that they 'did not affiliate with or construct a community - they built an audience' (McQuarrie et al., 2013, p. 146). However, it is important to point out that the focus of McQuarrie et al. (2013) was on the relationships between bloggers and their readers, not on the relationships between bloggers themselves. In relation to YouTube channels community has been identified among graffiti artists (Light el al., 2012) and music fan networks (Lingel \& Naaman, 2012). While the question of community generally has been discussed in relation to bloggers' and YouTubers' UGC activities, a number of sources see UGC creators as practitioners, for example 'Book Tubers' (Sorensen \& Mara, 2014) and graffiti artists using YouTube (Light et al., 2012). Schmidt (2007, online) links the idea of bloggers as both practitioners and as forming a community, theorising bloggers as 'communities of blogging practices'.

A CoP framework, however, offers a valuable alternative approach to online groupings generally, and to UGC creators specifically. Goulding et al. (2013) have demonstrated how offline consumer groupings can usefully be understood as a CoP. Dennen (2014) sees the academic bloggers in her study as forming a CoP according to Wenger's $(1998,2000)$ dimensions of CoP, but does not include video UGC creators in her study, and does not study a consumption-based context. Wenger et al. (2002) suggest that CoP theory is suited to consumer groups organised around practices. UGC creation has exploded online, much of it consumption-based: whether UGC creators constitute a CoP, learning in relation to their practices, is a valuable question to pose for managers who wish to seed products for trial, review, 
endorsement and promotion. In addition UGC content builds audiences, sometimes to significant scale, which is an element absent from general consumer groupings online, but which is of interest for managers to leverage. Therefore, the overall research objective for this study is identified as whether consumption-based UGC creators can be envisaged as a CoP (Wenger, 1998, 2000) to advance theorisations of consumption-based community online and managerial understanding of these important social influencers.

\section{Methodology}

\section{Context}

Of the genres of managerial interest on YouTube, beauty has outstripped all others in terms of consumer ownership of the online conversation: of 45.3 billion cumulative views of beauty-related material on YouTube, the vast majority, 95\%, are for user generated video, much of it involving demonstration (Pixability, 2015) presented by 'ordinary experts' (Tolson, 2010). A small minority has developed significant audiences and followings, and consequent celebrity status, for example, Michelle Phan (Pixability, 2015; Strugatz, 2014), Bethany Mota (Pixability, 2015) and Huda Kattan (Shapiro, 2017). There have recently been calls within consumer culture research for more research on blogging and bloggers (Arsel \& Zhao, 2013), and research on YouTubers is limited (Tolson, 2010). Beauty brand owners are therefore keen to understand beauty bloggers and YouTubers in particular in order to leverage their influence and audiences (WARC, 2011).

\section{Research questions}

Specifically, the study seeks to establish whether the beauty bloggers and YouTubers in this study demonstrate Wenger's $(1998,2000)$ three core characteristics of CoP and can thus be considered a CoP:

(a) Mutual engagement - Do the beauty UGC creators in this study (i) interact with one another, (ii) establish relationships, (iii) offer mutual support and (iv) engage in joint activities?

(b) Shared repertoire - are there communal resources in the form of such elements as language, routines, sensibilities, artefacts, tools, stories, styles and so on?

(c) Joint enterprise - Do they demonstrate 'a negotiated enterprise', 'an indigenous enterprise' and 'mutual accountability'?

Theory in relation to CoP is situated within a broader stream of social theories relating to practices, seen as inherently social and, from all perspectives, understood as involving learning ways of enacting practices and sharing understandings of what each practice means (Shove, Pantzar, \& Watson, 2012). Practice theories have been applied in both offline consumption contexts such as recreational pastimes (Shove \& Pantzar, 2005; Woermann, 2012), online contexts such as interior design, gardening and music (Arsel \& Bean, 2013; Hartmann, Wiertz, \& Arnould, 2015; Waldron, 2011, 2013) and in combined contexts such as snowboarding and YouTube (Woermann, 2012). 
A practice-based approach is particularly appropriate to a media-related study overall (Lehmuskallio \& Cruz, 2016), both because of the research context, but also because it allows us to identify both online and offline consumer practices, what kind of learning and sociality those practices involve, in what ways, and whether they combine to create community or a CoP.

Data collection began with an initial phase of secondary research to determine numbers of beauty bloggers and YouTubers within Ireland. Open online searches were conducted, utilising blog awards, newspaper articles and the Twitter address @lrishBeautyBloggers leading to a total of 460 blogs/bloggers/YouTube channels/ YouTubers. Each blog/YouTube channel was next checked to ensure that participants were over 18, living in Ireland, creating content in English, currently active with a sufficient history of content generation and not originating from a commercial environment. The total number of blogs/bloggers fitting these criteria prior to the recruitment stage was 182 of which 45 were also YouTubers. First phase research sensitised the researchers to the field and resulted in a strong familiarity with the overall range and style of beauty blog and beauty YouTube channel content. Second phase purposive qualitative sampling was carried out with a focus on blog/channel and blogger/YouTuber diversity. A total of 23 interviews were conducted with 25 participants of whom 12 were solely bloggers, 3 were solely YouTubers and 10 were currently or previously both as detailed in Table 1. Each participant's blog or YouTube channel was viewed online via a laptop, and discussed, as part of the interview. Blog and video texts were both analysed for the study as UGC content, as the focus was on UGC practices generally. Audio recordings were transcribed and thematic data analysis was conducted using NVivo software. In total 4445 blog posts and 1667 YouTube videos were reviewed, and analysed.

Table 1. Participant details and blog post and YouTube video counts to end July 2016.

\begin{tabular}{|c|c|c|c|c|}
\hline Blog/YouTube name & Participant name & Main media channel & Blog posts & YouTube videos \\
\hline Adoreabubbles & Sarah & (Lapsed YouTube) Blog & 297 & 128 \\
\hline Big Blonde Girl & Cat & Blog & 369 & NA \\
\hline Blather and Beauty & Leanne & Blog & 145 & NA \\
\hline Beautiful Health & Jess & Blog & 84 & NA \\
\hline Bright and Beautyfull! & Susan & Blog & 345 & NA \\
\hline Chasing Ruby Chat & Erin & YouTube Blog & 239 & 89 \\
\hline Eimear McElheron & Eimear & YouTube Blog & 407 & 153 \\
\hline Hail and Harmony & Emma Jane (with Zara) & Blog & 104 & NA \\
\hline Irish Beauty & Claire & YouTube & NA & NA \\
\hline JK Beauty Buzz & Julie & (Former YouTube) Blog & 67 & NA \\
\hline Latest Lil & Lily Joyce & Blog & 146 & 30 \\
\hline Laura's Views & Laura & YouTube Blog & NA & 94 \\
\hline LetzMakeUp & Siobhan & YouTube Blog & 696 & 815 \\
\hline Life with Lizzy & Elizabeth (with Michelle) & Blog & 54 & NA \\
\hline Makeup Over Mind & Orla & YouTube Blog & 335 & 94 \\
\hline Mardeline Miguel & Mardeline & YouTube & NA & NA \\
\hline Michelle Alice & $\begin{array}{l}\text { Mlchelle } \\
\quad \text { (with Elizabeth) }\end{array}$ & Blog & 166 & NA \\
\hline Naked without my Lippy & Holly & YouTube Blog & 37 & 98 \\
\hline Polished and Primed & Stephanie & YouTube Blog & 41 & 34 \\
\hline Pure Irish Sugar & Kate & Blog & 144 & NA \\
\hline Red Lips Red Hair & Amy & Blog & 364 & NA \\
\hline SheBBeauty & Sheena & YouTube & NA & 132 \\
\hline The Beauty Nook & Gemma & Blog & 208 & NA \\
\hline The Glamourelle & Zara (with Emma Jane) & Blog & 197 & NA \\
\hline
\end{tabular}


Data analysis adopted a blended netnography (Kozinets, 2010) approach combining online and face-to-face data in line with recent research on blogging (Dolbec \& Fischer, 2015) guided by an understanding of Spiggle's seven analytic operations, which are neither 'discrete ... nor ... sequential' (Spiggle, 1994, p. 493). Categorisation for Spiggle (1994) is 'the process of classifying or labeling units of data during the process of coding' (p. 493). In this study, coding followed Miles, Huberman, and Saldaña's (2014) widely adopted approach to qualitative data analysis, which is suitable for offline, online and visual data. For the latter, Miles et al. (2014) advocate analysis of images in a holistic way, via analytic memoing, which is compatible with contemporary approaches to visual analysis (Rose, 2016). A theoretical orientation to the research in the form of sensitising concepts of community and practice was adopted, offering reference and direction (Patton, 2015) and guiding the process of abstraction outlined by Spiggle (1994). Early data analysis concurrent with data collection was conducted, as advised (Miles et al., 2014), and three broad categories of 'provisional codes' were assigned: hunch codes (Miles et al., 2014; Saldaña, 2011) from the data gathering process and a review of observation, setting and interpretation notes (Richards, 2014); In Vivo codes from the transcripts and online text; and structural codes suggested by interview questions (Miles et al., 2014; Saldaña, 2011). These early codes were subject to a comparison process, as advocated by Spiggle (1994), where they were reviewed for similarity and difference. These first round codes also guided 'subsequent data collection' (Spiggle, 1994, p. 494): for example the In Vivo code 'community' emerged in first round coding and guided the sampling of community-based events, described below, as part of the data collection process.

The process of coding was iterative (Spiggle, 1994). Coding cycles are the norm in this approach, along with analytical memoing, using a movement between data, memos and theory to ensure that the relationship between theory and data is robust (Silverman, 2011). A second round of coding eliminated simultaneous or double coding and holistic codes assigned to large sections of text. Magnitude coding, for 'intensity, frequency, direction, presence or evaluative content' (Miles et al., 2014, p. 80), does not require quantitative analysis per se, and has been identified as useful in categorising online data (Saldaña, 2011). In the process of second round coding this transpired to be the case in this study in relation to volume of blog posts and video types; consequently new online data were gathered, reviewed and coded in the light of this.

Categories identified in first and second round coding were abstracted into more general constructs, as Spiggle (1994) advises: for example codes for UGC content created such as 'tags', 'group photos' and 'collabs' were abstracted into a more general classification of 'content'. Similarly, empirically grounded codes, such as 'twitter meet-ups' and 'online chat' were abstracted into a more general classification of 'social contact'. This higher order analysis was further refined by reviewing codes in the light of constructs identified: viewed in the light of the concept of cooperative content creation, for example, content codes such as 'tags' were re-classified. Analysis moved across constructs horizontally, and between levels of analysis, vertically, in a process of integration of analytical elements (Spiggle, 1994). Thus not alone was the coding process iterative but so was the overall process of analysis as Spiggle (1994) advises, here cycling from theory to data and back, until theoretical saturation was achieved. 
The refutation process proposed by Spiggle (1994) was partially conducted via subjecting the analysis to empirical scrutiny in comparison with contemporaneous industry accounts of blogger and YouTuber UGC activity. However, purposive sampling of a negative case as Spiggle (1994) suggests did not prove possible in this study, as looking for bloggers or YouTubers on the basis of their non-involvement in a CoP did not prove a practical recruitment criteria. Testing the analysis in alternative contexts, as Spiggle (1994) also suggests, was outside the scope of this study, but is included as a recommendation.

\section{Findings}

The beauty UGC creators in this study, and their blog and video outputs are considered in relation to the core characteristics of CoP identified by Wenger $(1998,2000)$ - mutual engagement, shared repertoires and joint enterprise - and the three modes of belonging to CoPs - engagement, imagination and alignment - are also considered inter alia. Table 2 summarises how elements of the dimensions of practice (Wenger et al., 2002) are found among the beauty bloggers and YouTubers in this study.

\section{Mutual engagement}

Mutual engagement is identified among the beauty UGC creators in this study along the four dimensions outlined by Wenger (1998, 2000): social interaction, relationships, mutual support and joint activities.

\section{Social interaction}

Social connection is a fundamental element of community, whether consumption-based or CoPs (Wenger, 1998). Whereas, previous researchers identified networked sociality between bloggers via blogrolls or comments (Blanchard, 2004; boyd (sic), 2006; Kozinets et al., 2010; Walker Rettberg, 2008), and between YouTubers via comments (Lange, 2009; Lindgren, 2012), here we find social connection online both on and beyond the blog or YouTube channel itself, and that it is enacted via multiple social media platforms. Twitter is universally used by participants and is described by Amy as '... a very powerful resource in the bringing together of bloggers and YouTubers'. Facebook chat is also common and in general participants reported regular and widespread contact making no distinction in vocabulary for verbal and written exchange: '... they talk in the community with everyone' (Cat); '... talk to each other over the blogs and over e-mail' (Julie); 'we converse via social media' (Gemma); '... talking on Twitter, chatting on Facebook' (Leanne).

Where previous research suggests that blogger and YouTuber social connection is entirely virtual (boyd (sic), 2006; Light et al., 2012; Lingel \& Naaman, 2012; Walker Rettberg, 2014), on the contrary, the participants in this study report that meeting in person as a result of writing a beauty blog or maintaining a YouTube channel is common, both individually and amongst groups. UGC creator events tend to be referred to as 'meet-ups': 'a whole day for us (bloggers) ... where we could all interact and get to know each other' (Eimear); or the 'Irish Beauty YouTubers meet up' (Sheena). Commercially generated events also provide opportunities for social interaction, 


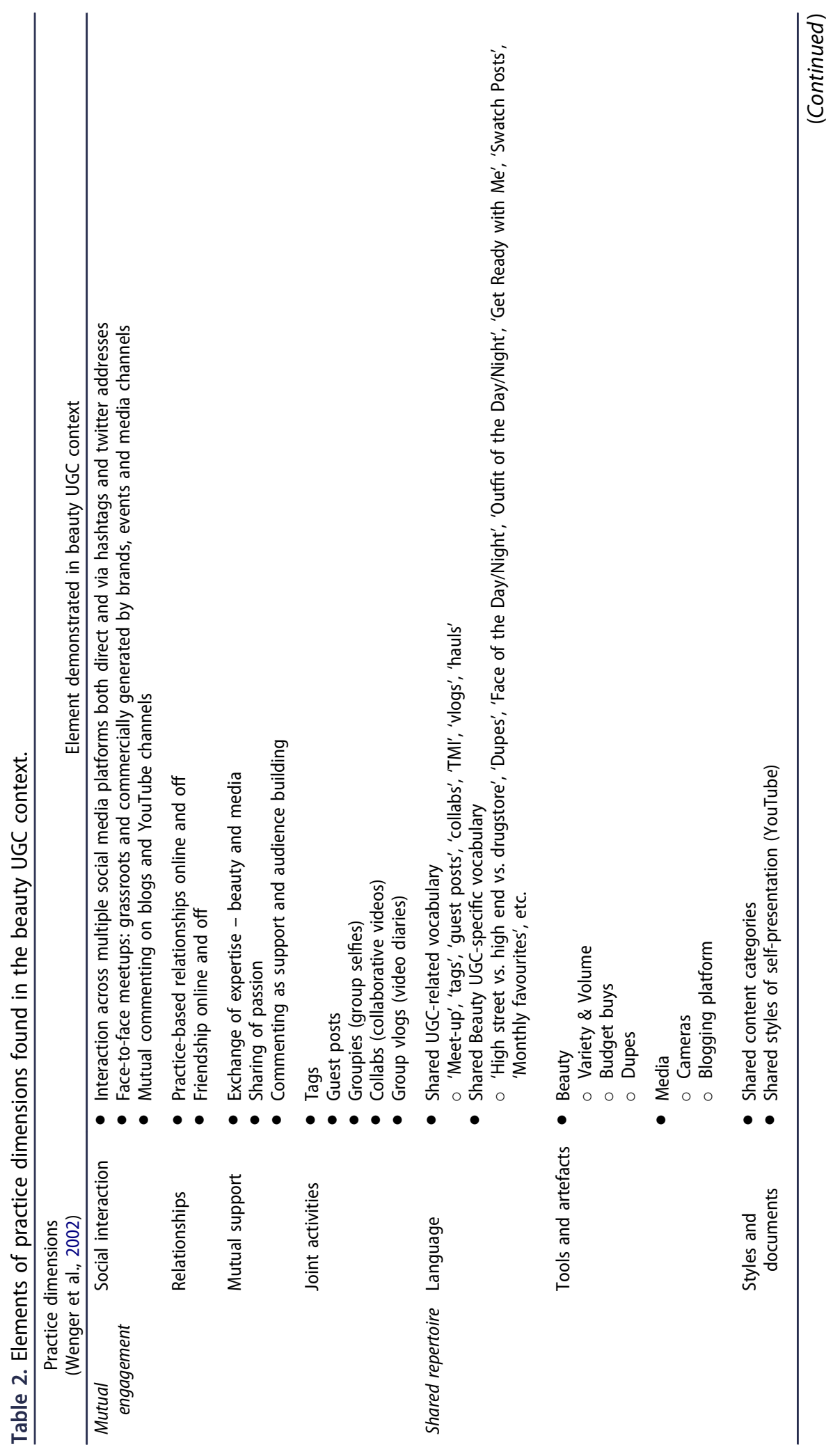


exchange and learning, and access to new products, whether brand generated such as product launches, those created by general commercial interests such as blogging seminars, or media channel generated such as a YouTube Creators' Day.

\section{Relationships}

As described above, the UGC creators in the study interact both online and face-to-face, forming relationships relating to their practice in the process. Even where there is no face-to-face relationship as Julie explains 'we might never meet. But we're still kind of buddies or friends online'. All the YouTuber participants are members of a private Facebook group for Irish beauty YouTubers. In addition there are several private groups and networks.

Where the bloggers and YouTubers in this study discussed social interaction, friendships and relationships they were referring to peer bloggers and YouTubers. This suggests that where Blanchard (2004) and McQuarrie et al. (2013) focused on community vertically, between bloggers and their audiences, this only tells part of the story. In our study, the social connection is horizontal, between bloggers and between YouTubers.

\section{Mutual support}

Mutual support is identified throughout the literature on community and consumption community as a core element (Blanchard, 2004; Thomas et al., 2013) and by Wenger (1998) as part of mutual engagement within a CoP. Among the beauty bloggers and YouTubers in this study three different kinds of mutual support and sharing are identified: exchange of expertise, general opportunities to share an interest and commenting on blog sites and YouTube channel content. In the first of these cases bloggers provide specific technical support to each other in various ways in relation to collaborative content creation joint activities as detailed below. In the second case interaction with fellow bloggers and YouTubers provides an opportunity to discuss and share a mutual interest. According to Gemma 'the same interests pulls you together for sure'. This depth of interest is not available with peers or general social contacts outside of the practice. As Claire puts it: 'It's really good to talk to people who really get it'. The third type of mutual support takes the form of commenting on blogs and YouTube channels as a form of social connection, but also done as a form of support. Leanne describes how the beauty bloggers in the study 'all kind of read each others' posts and comment ... You make it an active thing to comment on each others' posts at least once a week'.

\section{Joint activities}

Joint activities have been identified as a key aspect of community generally and CoPs in particular (McMillan \& Chavis, 1986; Wenger, 2000). Both bloggers and YouTubers participate in joint activities in relation to cooperative content creation of which five specific practices are identified: one shared by bloggers and YouTubers (Tags), two by bloggers only (guest posts and groupies) and two by YouTubers only (collaborative videos ('collabs') and group vlogs).

While previous researchers have identified blogrolls as a linking function among bloggers (boyd (sic), 2006) here we identify tags as the first kind of joint content creation type that function as a kind of chain challenge 'that circulates around' (Sheena), linking 


\section{THE MAKEUP ADDICT TAG}
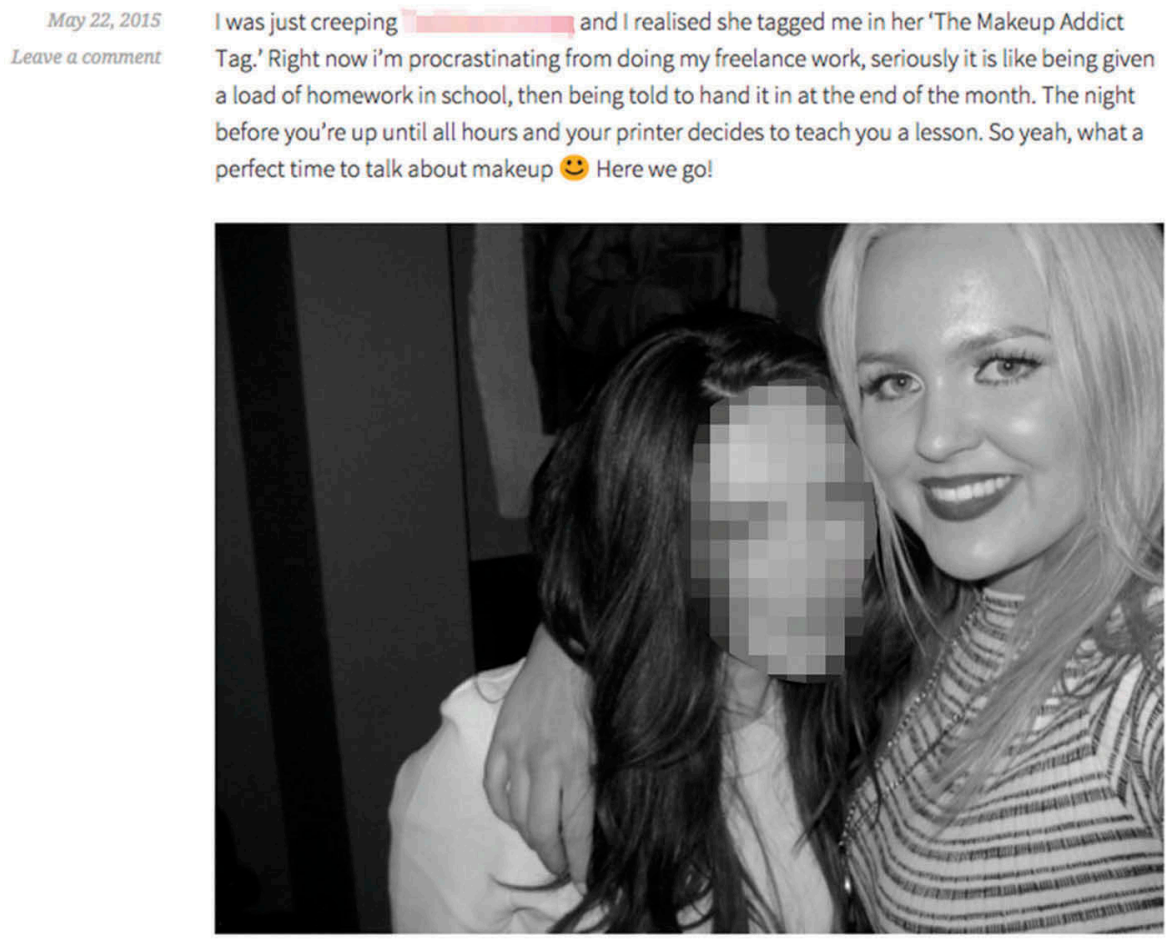

Figure 1. Tag Blog Post.

blog to blog and YouTube channel to YouTube channel and thus making visible social connections (Muñiz \& O'Guinn, 2001). Figure 1 shows a tag post from Holly's blog.

Tagged posts are advantageous in broadening the audience for individual blogs or YouTube channels, allowing bloggers and YouTubers to gain visibility among potential readers via peer content-creator sites: the larger the audience the greater potential to monetise the channel or blog, an entrepreneurial avenue for UGC creators (Burgess \& Green, 2009) such as suggested by Canniford (2011a) as available to consumer tribes.

Again social connections are made visible (Muñiz \& O'Guinn, 2001) by the second and third kind of joint content creation identified in this study: a guest post and a groupie. $A$ guest post is where one blogger invites another to write for their blog: 'it's usually when people are going on holidays and they want to keep their content regular' (Amy). A groupie is a group selfie (Feifer, 2015) that is often taken by the bloggers at meet-ups offline, as exemplified by Figure 2.

The fourth type of mutual content creation is a 'collab' (collaboration) where two, or more, individual YouTubers create linked or related video content. This is often done individually or remotely and edited together, and is then posted on the channel of each YouTuber involved, as shown in Figure 3. The fifth type of mutual content creation is a vlog, understood by the YouTubers in this study as a video shot diary-like, on the move, sometimes in a domestic setting, but often on an out-of-home trip, unlike prior literature which defines a vlog as a straight-to-camera monologue (Molyneaux, Gibson, O'Donnell, 

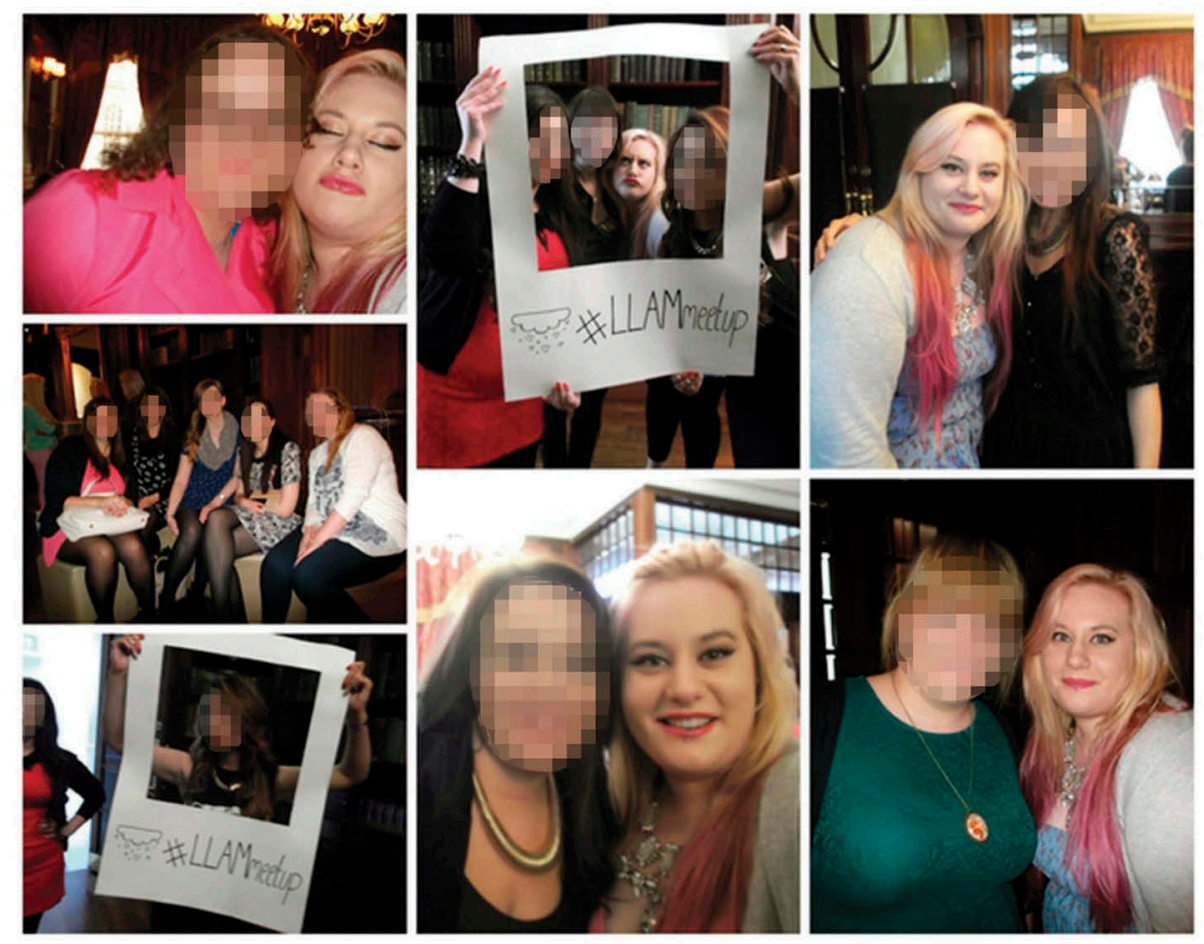

Figure 2. Beauty Blogger Groupies.

\& Singer, 2008). Where this is done by two or more YouTubers together it is termed a group vlog, taken as records of group activities and meetups. Figure 4 shows a still from a YouTuber meet-up weekend.

\section{Shared repertoires}

A third key dimension of community creation via practice is a shared repertoire, which, depending on the practice domain, is exemplified by some elements such as language, routines, sensibilities, artefacts, tools, stories, styles, documents and so on (Wenger, 2000). In relation to the beauty UGC creators in this study shared repertoires are observed in relation to three categories of resources: language, tools and artefacts, and styles and documents.

\section{Language}

Schatzki (2012) is clear in identifying that the presence of a specific vocabulary is a good indication of the presence of a practice generally, and Wenger $(1998,2000)$ identifies a shared repertoire of language as an indicator of the creation of community via practice. Among the bloggers and YouTubers in the study a clear shared vocabulary is identified. As already referenced above, the terms 'meet up', 'tags', 'guest posts', 'collabs', 'TMI' and 'vlogs' indicate that a specific vocabulary for content creation practices circulates among 

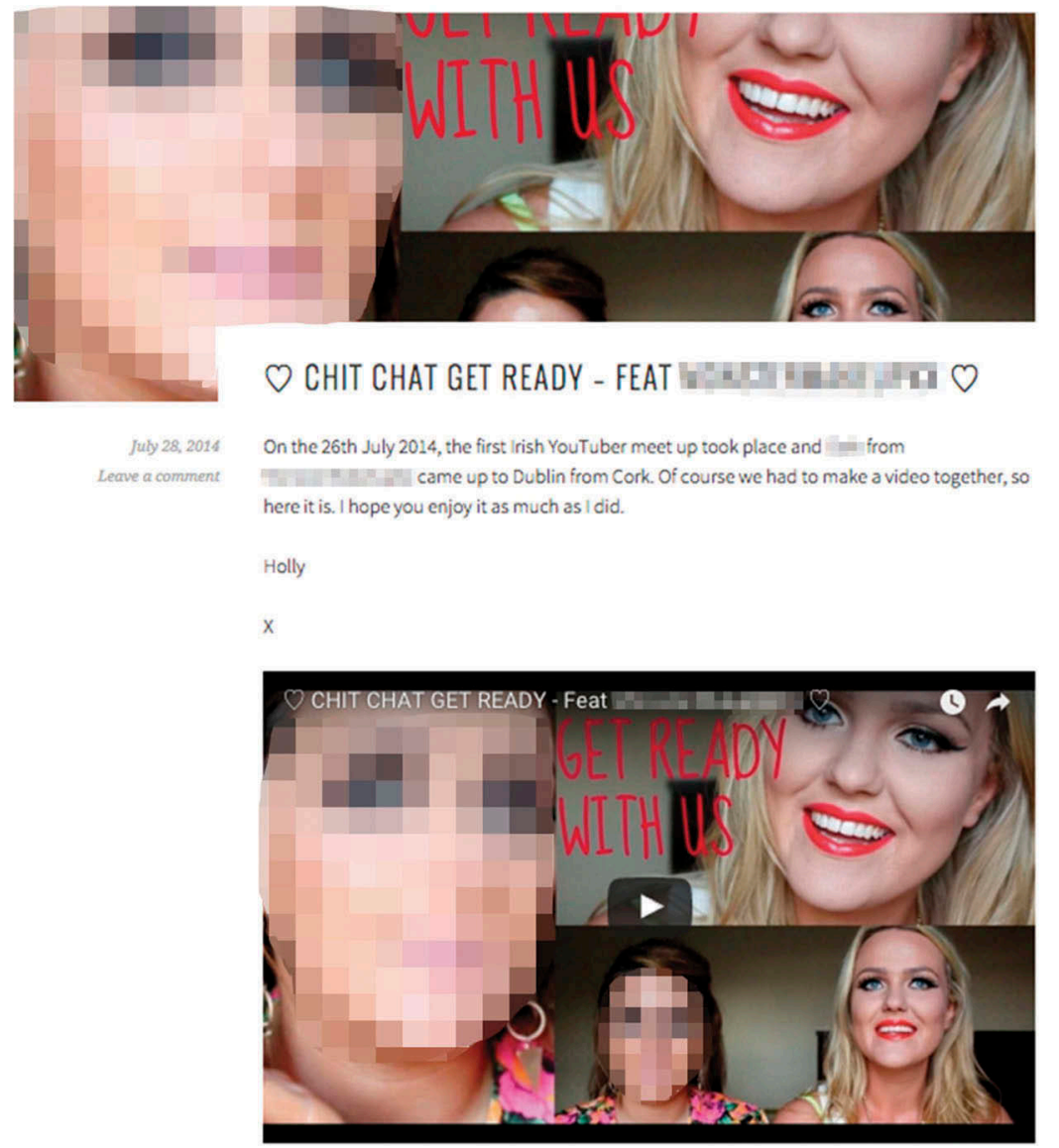

Figure 3. YouTuber 'Collab'.

the UGC creators in the study. Hauls (shopping sprees) were mentioned by several participants in the study, have spawned a category of blog post and video of their own (Harnish \& Bridges, 2016; Jeffries, 2011) and are a common UGC type in the blogs and YouTube channels reviewed for this study.

While the vocabulary above is an indication of the presence of a UGC practice domain generally, specific beauty UGC vocabulary is also identified among the bloggers in this study. Participants in the study referenced 'High Street (versus) ... high end' (Claire) or 'high end (versus) ... drugstore' (Erin), as specific price categories into which the product category, and their UGC, fall. They regularly search for substitute cheaper products they refer to as 'dupes' (duplicates). Recurrent video or blog post types are identified by participants using specific beauty UGC vocabulary, such as 'Face of the Day/Night', 'Outfit of the Day/Night', 'Get Ready with Me', 'Swatch Posts', 'Make-up Look', 'Monthly Favourites' and 'I Used it All Up', which are among those detailed in Table 3.

Furthermore all of the participants in the study discussed one or all of the following: formally joining the Irish Beauty YouTubers Facebook group, following the @lrishBeautyBloggers twitter address, using the tag Irish Beauty YouTuber (so that '... when we typed in that we'd all come up' (Julie)) and informally identified both as a 


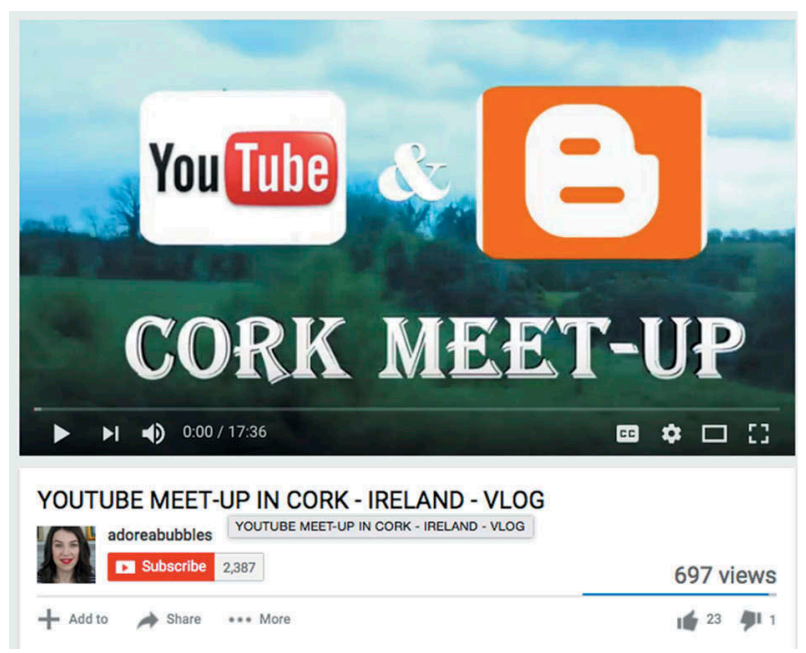

Figure 4. Meet-Up Vlog.

Table 3. Common blog post types among participants in this study.

\begin{tabular}{|c|c|}
\hline Blog post type & Description of blog post type \\
\hline $\begin{array}{l}\text { Budget Buys/High Street vs. } \\
\text { Drug Store }\end{array}$ & Comparison of products at different price categories \\
\hline Event Posts & Discussion of an event attended by the blogger. \\
\hline $\begin{array}{l}\text { Face of the Day (\#FOTD) } \\
\text { Face of the Night (\#FOTN) } \\
\text { Outfit of the Day (\#OOTD) } \\
\text { Outfit of the Night } \\
\text { (\#OOTN) }\end{array}$ & $\begin{array}{l}\text { Specific combination of make-up suggested for daytime or night-time context } \\
\text { showcasing bloggers' own choices and daily life. Fashion bloggers' version of this, } \\
\text { shows the outfit chosen for the day or event, and some beauty bloggers combine } \\
\text { both. }\end{array}$ \\
\hline 5 Minute Make Up & Discussion of how to apply make-up in a short time limit. \\
\hline Get Ready with Me (\#GRWM) & Step-by-step guide to make up application as if observing the blogger getting ready. \\
\hline Hauls & $\begin{array}{l}\text { Description of several products purchased or acquired at one time, perhaps at an } \\
\text { event. Also used by fashion bloggers and beauty YouTubers. }\end{array}$ \\
\hline Make-Up Look & $\begin{array}{l}\text { Similar to \#FOTD and \#FOTN but in more general contexts e.g. wedding or evening } \\
\text { event make-up look. }\end{array}$ \\
\hline $\begin{array}{l}\text { (Monthly) Favourites/l used } \\
\text { it all up }\end{array}$ & $\begin{array}{l}\text { Discussion of what has been used during the preceding month, or the most used } \\
\text { products during that time. }\end{array}$ \\
\hline New Releases & Review of products that have been recently launched. \\
\hline Pictorial & $\begin{array}{l}\text { Similar to a \#GRWM specifically using photographs for step-by-step make up } \\
\text { application. }\end{array}$ \\
\hline Review & Discussion of the performance of a product. \\
\hline Seasonal & Discussion of a make-up look, or products suitable for a particular time of year. \\
\hline Swatch & $\begin{array}{l}\text { Discussion of multiple products from a single category photographed and shown side } \\
\text { by side, usually on the bloggers' skin, much as paint might be trialled on a wall. }\end{array}$ \\
\hline The Top F & Blogger's ranking of products in a particular category or on a particular criterion. \\
\hline Wish List & \\
\hline
\end{tabular}

'beauty blogger' or 'beauty YouTuber' and an Irish one, consistently talking about themselves as a collective, referring to their collective practices ('we', 'us') and using the word community which emerged as an In-vivo code at the data analysis stage. All of this language indicates the presence of a specific practice (Schatzki, 2012), a specific CoP (Wenger, 1998, 2000) and also indicates identification with a national practice-based identity, in line with theorisations of the mutual development of identity along with practice (Nicolini, 2012; Wenger, 1998, 2000). 


\section{Tools and artefacts}

Beauty UGC requires two sets of tools and objects: the first in relation to beauty practices, and the second in relation to media. In the first place, beauty materials are an essential prerequisite for the practices and three salient shared dimensions of beauty materials arise in this analysis: the variety and volume of materials used, the dominance of price sensitive consumption in the form of budget buys and the search for and testing of duplicate products.

Beauty bloggers and YouTubers need an ongoing supply of new products, to satisfy audience demands: '... people don't want to see you using the same make up all the time' (Eimear); 'if it's brand new and it's hot on the market people are going to Google to see it' (Gemma). The second significant aspect that is prominent in relation to the use of beauty materials is the focus on budget buys. Of these categories several bloggers and YouTubers in this study explicitly identified as budget/pharmacy/drug store - Cat focuses on 'affordable brands', Claire is 'definitely High Street', Julie uses 'a lot of budget stuff', Erin doesn't 'go towards (high-end) that often' and Sarah says she never talks 'about really high end products'. The third salient element of the use of beauty materials is in relation to a practice reported by several of the participants, as already mentioned above, was the search for what they refer to as 'Dupes', or duplicates, '... the cheaper version'(Erin); '... the exact same' substitute (Julie); '...the same product just different packaging'(Holly). There is clear evidence here of shared types of tools, and alignment of practices to community norms.

The second set of tools and objects required by beauty UGC creators relate to media products of which two broad categories are identified: cameras and related materials; and the media platforms via which their digital content is disseminated. Cameras are carefully researched via blogger and YouTuber networks and equipment is also chosen with reference to the group. Several participants referenced using a Canon camera, and Gemma identified that this brand as the most commonly used by fellow YouTubers and bloggers. A further tool is the social platform in which the beauty UGC content is disseminated. Blogging and YouTubing platforms serve to distinguish this kind of UGC creation from other kinds of online creativity (Walker Rettberg, 2008). All the bloggers interviewed were using either Blogger or WordPress with Blogger as the favoured choice, selected because it is seen as the most widely used (Kate), is identified 'through other bloggers' (Zara), is 'standard' (Deirdre) and 'the one that everyone' uses (Zara), again demonstrating the process of identification with the community and alignment with community norms. All video UGC in the study was on YouTube as a primary video channel, consistent with observations from the industry literature that YouTube still remains dominant for video UGC (Ballve, 2015) and for beauty YouTubing in particular (Pixability, 2015).

The use of beauty products and media UGC production materials indicate clear, distinct practices in their own right. However, as Wenger (1998, 2000) and general practice theorists (Schatzki, 2012; Shove et al., 2012) have extensively outlined, practices have overlaps at the boundaries with other practices. However, the combination of both sets of tools and artefacts here is an indication of a very specific practice sphere, and is evidence of shared repertoires identified as an element of CoPs by Wenger $(1998,2000)$. 


\section{Documents and styles}

The third dimension of shared repertoire that is in evidence in this study is the overlaps and similarities between bloggers and YouTubers in UGC written and visual content and its style. The beauty UGC content in this study is similar on two dimensions: content is produced in similar content categories; and on YouTube specifically similar self-presentation styles are put forward.

As already outlined above Irish beauty bloggers and YouTubers engage in a range of five different kinds of joint content creation: tags, guest posts, groupies, 'collabs' and group vlogs. However other non-collaborative practices can also be identified as converging across the group. The beauty UGC content created by the bloggers and YouTubers in this study is produced in a limited number of recurring categories, and this is common within the wider blogging and YouTubing community as identified by Pixability (2015). Globally $45 \%$ of all beauty YouTuber videos are tutorials - a make-up technique teaching video (Pixability, 2015) - and $41 \%$ of the videos in this study are also tutorials as detailed in Table 4. In relation to beauty blog post types no international reference point is available, nor are playlist equivalents posted by beauty bloggers. However participants were asked to identify the most common blog post types they created, and a range of recurring blog post types were collated from this, and verified against blog post headings, where available. These recurring blog post types are detailed in Table 3.

Both bloggers and YouTubers in the study were clear that their reference group is consulted in deciding what material to post:

Orla The monthly favourites are... one of the biggest things... like we'll say within the community... "Oh yeah, favourites videos time"... because everyone nearly, like over the space of a week...(posts).

Leanne You'll get an idea going, oh okay, so for example, "The Five Minute Makeup", somebody put up what their routine was, and I was like "Oh I will do mine".

A second dimension of shared style is in evidence in relation to self-presentation on YouTube. Like the YouTubers in Tolson's (2010) study, the beauty YouTubers here stage themselves as authentic via speech, modes of address and setting. This establishes them as 'ordinary' (Tolson, 2010) and creates a kind of intimacy as Berryman and Kavka (2017) have identified in relation to YouTuber Zoella. Self-disclosure is also common via integrating small personal details, or contextualising the content within the YouTuber's social world. Holly's video titled 'Simple Contour, Blush and Highlight Routine' (14 June 2014) offers personal disclosure opening: 'I haven't put up a video

Table 4. Beauty video categories aggregated from participant playlists.

\begin{tabular}{llc}
\hline 1 & \multicolumn{1}{c}{ Tutorials } & 41 \\
\hline 2 & Reviews \& favourites & 24 \\
3 & Hauls & 7 \\
4 & Vlogs & 7 \\
5 & Equipment & 4 \\
6 & Tag & 4 \\
7 & Other & 13 \\
& & $100 \%$ \\
\hline
\end{tabular}


in a while. I had a really bad accident... and I was in hospital and I was on pain killers'. Laura's series of waxing videos are set in her broader social world, shot in the same genre as a reality television show, taking the viewer by the hand to show an intimate personal experience, using in situ to-camera presentation (Aslama \& Pantti, 2006; Biressi \& Nunn, 2012; Tolson, 2010). Beauty material is often interspersed with a confessional style as in the reality TV genre (Allen \& Mendick, 2013) involving personal journeys of discovery (Amy references her struggles with anxiety; Holly her coming to terms with her height) thus establishing an aesthetic of the ordinary (Allen \& Mendick, 2013). All of the YouTube videos are produced in a similar format, either as to-camera monologues shot in domestic settings or vlogs - diary style on the move, in the home or externally, showing a vignette from the YouTuber's life (Tolson, 2010).

\section{Joint enterprise}

The third characteristic of CoP identified by Wenger $(1998,2000)$ is the presence of what he terms 'joint enterprise', meaning that members have a collectively developed understanding of what their community is about and can make an account of the community and its practices. This is observed among the beauty UGC creators in this study along the three dimensions outlined by Wenger (1998, 2000): negotiated enterprise, indigenous enterprise and mutual accountability.

\section{Negotiated enterprise}

Negotiated enterprise for Wenger $(1998$, p. 78$)$ is 'a collective process of negotiation that reflects the full complexity of mutual engagement' and 'does not mean agreement in any simple sense' but rather that the practices of the community are 'communally negotiated'. Mutual engagement is a prerequisite for the presence of a negotiated enterprise then, and this is observed among the beauty UGC creators in this study as outlined above via a rich and complex variety of social interaction, relationships, mutual support and joint content creation activities. Practices and identities in the UGC beauty sphere are negotiated on an ongoing basis. The first phase of engagement involves a process of socialisation to the practice, via 'legitimate peripheral participation' (Lave \& Wenger, 1991), where new bloggers and YouTubers often begin as viewers and readers of existing material and model their initial outputs accordingly: 'I'd been watching them for years. Watching them and learning how to do my make up and then I just got really interested in it' (Claire). However, while content creation is aligned to norms there is ongoing tension between replicating peer content creation styles on the one hand (vis Amy 'I do read a lot of blogs and I would say that I take some inspiration'), and distinguishing the UGC content from others, on the other hand, as Elizabeth and Kate explain:

Elizabeth It's something a lot of people have done different...I've tried to make it my own. And obviously choose different products to what they've used.

Kate ...when I say inspiration I don't mean like "Oh they've done that I'm going to write about that" but I see like their style, and I'm kind of like "Oh maybe I could use that but in a different way"...You know like you kind of want to make yourself a bit different. 
A key area for negotiation for UGC content creators is the degree and nature of commercialisation of their content, and to what degree, and how this is disclosed. The UGC creators in this study all state that they declare any commercial sponsorship received ('I'll always say if I bought stuff myself or if I was sent it' Laura) but several bemoaned the practices of other UGC creators whose content they view as obviously commercial but without disclaimers ('...her videos are all sponsored... she said [brand name] about 150 times' Laura). This mirrors concerns in the wider marketing communications sphere where advertising standards bodies have sought to enforce disclaimers on UGC creators generally.

\section{Indigenous Enterprise}

A CoP is an indigenous enterprise in the sense that it is always 'produced by participants within the resources and constraints of their situation' according to Wenger (1998, p. 79). Although Wenger (2000) encourages theorisations of CoP around consumer groupings, and this study is not the first empirical study of consumer CoP (e.g. Goulding et al., 2013), Wenger's $(1998,2000)$ theorisations of CoP usually describe organisational settings, where the indigenous nature of the enterprise may be harder to identify given that participants are generally employees. Here however, in this consumer grouping there is a clear indigenous character to the practices. Beauty UGC creators are grass-roots innovators, discovering the practices themselves, standing on the side-lines for a while as referenced above, and then participating on their own terms. This is not to say that the practices of this community, just as for others identified by Wenger (1998), are not shaped by forces outside the community. In this case there are broader forces at work in the form of commercial brand and media interests, as we have seen, providing materials (beauty brands) and tuition (YouTube Creators' Day).

However just as Wenger (1998, p. 79) describes it, the UGC practices here are produced within constrained resources: hence the budget buys and 'dupes' above, the carefully researched equipment buys, or the absence of equipment at all sometimes, for example lighting ('I just use the natural light that comes into my bedroom' Holly). While UGC content references the local UGC peer group and the global beauty UGC context, and despite constraints, content creation is also playfully innovative at a micro level, just as Dolbec and Fischer (2015) observe among fashion bloggers, and Burgess and Green (2009) observe among UGC creators generally.

\section{Mutual accountability}

Wenger's $(1998,2000)$ concept of mutual accountability references the interconnectedness of practices, competences and meanings in a practice domain, and is not intended to indicate mutual responsibility. Shared repertoires of language, artefacts and styles outlined in detail above serve to create a practice domain of shared values around what counts as beauty blogging. Convergence of activities, normed to a point in relation to global and local UGC creators is further evidence that there is a shared understanding of the nature of the practice. At the same time Wenger (1998, 2000 ) is keen to indicate that individual responses vary from one practitioner to another and that practices are not regulated or fixed. Indeed as already outlined above the UGC creators in this study are keen to differentiate their styles and 
content the better to distinguish their blog or channel from peers who may also be competitors in a broad sense as outlined above. Consequently ongoing development of beauty UGC is enabled and characterised by the incremental micro-innovations such as identified by Dolbec and Fischer (2015) and Burgess and Green (2009) here brought about by the tension between normed and differentiated content. This process feeds directly into Wenger's $(1998,2000)$ notion of mutual accountability in the sense that the practice domain becomes a system of interconnected responses.

\section{Summary: elements of practice dimensions found in the beauty UGC context}

Wenger (1998) identifies three dimensions of practice which combine to produce a community from that practice: mutual engagement, a shared repertoire and joint enterprise. Elements of all three are clearly observed in the beauty UGC context in this study; first via patterns of social interaction; second via shared language, tools, documents and styles; and third via ongoing balancing of grass-roots innovations with mutual alignment to reference group UGC practices.

\section{Discussion}

To understand a consumption community as a CoP according to Wenger $(1998,2000)$ three dimensions of practice must be observed: mutual engagement, a shared repertoire and a joint enterprise. The beauty UGC creators in this study demonstrate elements in each dimension, as detailed in Table 2. First all four elements of mutual engagement are in evidence: they engage in regular social interaction, both online and offline; they form relationships relating to their practice; they offer each other mutual support; and they engage in joint activities in relation to content creation in a variety of ways.

The second of Wenger's $(1998,2000)$ core dimensions of CoP is found in the shared repertoires of language, tools and artefacts, and documents and styles among the respondents in this study. Language from the broader community of UGC practice is in evidence, and more specifically a distinct vocabulary relating to beauty UGC circulates among the bloggers and YouTubers participating. They use beauty and media tools and artefacts in common, as might be expected, but combine them as beauty UGC creators in ways that are specific to the practice domain (Wenger, 1998, 2000). A third shared repertoire is to be found in the visual and written documents and videos they produce, aligning broadly with content produced in the global beauty UGC community, and influenced with reference to the local UGC community. Their style is informed by a shared style of self-presentation in the case of YouTube videos, which emphasises intimacy (Berryman \& Kavka, 2017), ordinariness and authenticity, along with expertise in the manner of hybrid 'ordinary experts' (Tolson, 2010).

The third of Wenger's $(1998,2000)$ dimensions of practice is found in the ongoing negotiations between beauty UGC creators' individual differentiation, on the one hand, and their referencing of the other beauty creators' UGC, on the other hand. They learn how to be beauty bloggers and YouTubers from observing existing practices, and gradually become creators in their own right, while never losing sight of the need to broadly align with practices in the domain. Overall dimensions of CoP, as defined by Wenger $(1998,2000)$ are clearly in evidence among the UGC creators in this study. 
Evidence of how UGC CoP forms emerges inter alia from the practice dimensions here. Beauty bloggers and YouTubers begin on the periphery (Lave \& Wenger, 1991), reading, watching and learning how beauty blogging and YouTubing is done. To identify as beauty UGC creators, make connections, learn, access beauty products and access audiences, they form connections with other creators via direct social connection, networks (Twitter and Facebook) and face-to-face events. They provide mutual technical and social support and they engage in joint activities, which deepens their learning and social connection.

This study reverses the previous theorisations of Schau et al. (2009) and Goulding et al. (2013) who see brand communities and consumer tribes, respectively, as exhibiting elements of practices or CoP. Here we see practices first, thus creating a CoP. This CoP simultaneously functions as a consumption based community, and exhibits some elements of consumer tribes. Our findings clearly demonstrate that community does not contain the practices here (Fuller, 2007; Nicolini, 2012): rather that the practices bring forth the community, via mutual engagement, shared repertoires and joint enterprise.

In addition we find that beauty UGC creators are playful and entrepreneurial which is consistent with findings from media studies researchers in relation to other UGC creators (Burgess \& Green, 2009) and is also consistent with conceptualisations of the practices of consumer tribes (Goulding et al., 2013). This suggests that conceptualising a consumption-based UGC activity as a CoP is complementary with previous theory relating to UGC creators and relating to consumer tribes.

A practice theory approach has proven very appropriate in this context supporting Nicolini's (2012) observation that practices carry community and extending Schau et al.'s (2009) research on practices in brand communities. In defining practices as the unit of analysis this approach avoids the narrow focus on either online content alone on the one hand, or consumer perspectives alone on the other. The blended data yields a holistic understanding of the practice and a deeper understanding than approaching blogging and YouTubing as if entirely virtual.

Too often, as Canniford (2011b) and Goulding et al. (2013) point out, research on consumer tribes offers little that managers can leverage to their advantage, and different kinds of consumption community must be seeded in different ways. Goulding et al. $(2013$, p. 826) suggest that understanding the clubbers in their study as situated learners could be used by managers to 'offer products and services as learning resources'. Likewise the insights put forward here in relation to beauty UGC creators as forming a CoP are of value to managers as they indicate that consumption-based UGC activity in this context involves ongoing learning of beauty, media and presentation techniques. The beauty UGC CoP can be understood as a community of hybrid beauty and media practitioners, connected by their passions, learning and deepening expertise. Uzunoğlu and Kip (2014) suggest that brand managers should facilitate generally the activities of bloggers as brand ambassadors. Here we propose specifically that offering the bloggers and particularly the YouTubers in this study support and training, as participants described they have received from Benefit, Isadora and The Body Shop (beauty products and techniques) and YouTube (media) is a fresh and valuable way to build relationships with them, while simultaneously enabling them to build and maintain the peer relationships they so value and the credibility their audiences require (Kozinets et al., 2010). 
Furthermore, as Berryman and Kavka (2017), Morris and Anderson (2015) and Tolson (2010), among others, have pointed out in relation to YouTubers in particular, the selfpresentation of these beauty UGC content creators as intimate friends, and authentic consumers, creates new challenges for managers in the beauty sphere. Traditional persuasive advertising executions and campaigns showing highly stylised environments must be reviewed in the light of a beauty ecosystem that in becoming increasingly dominated by UGC from 'real' consumers in 'real' contexts. In addition consideration must be given to collaboration with beauty UGC creators as partners in promotional activities, either via blogger/YouTuber celebrity endorsement within traditional advertising formats for 'star' UGC creators or via brand partnerships and sponsorships designed to leverage the blogger/YouTuber audience channel - as trend-setting beauty brands such as MAC and Becca have done with their recent product collaborations with beauty YouTubers (Hall, 2017; Weinsweg, 2017). A further option for brands is to adopt beauty blogger/YouTuber type content, such as tutorials, and to develop their own online beauty material, with the same grass-roots personal and authentic feel as the beauty UGC CoP style.

This research is limited to Irish beauty UGC creators, to one specific geographic location, and to one consumption domain. Future research might consider whether the findings here in relation to beauty UGC CoP hold in other countries and contexts. The beauty bloggers and YouTubers in this study were all resident in the Republic of Ireland, a country small in geographic and population scale. It would be interesting to see if the findings here differ in other geographic locations, and also if size of population plays a role, particularly in relation to the role of shared competences and community meetups.

In addition, notwithstanding the growth of male grooming practices (The Economist, 2015), and the emergence of some male beauty YouTubers (Hess, 2016; Safronova, 2016), beauty blogging and YouTubing are overwhelmingly female gendered practices. An exploration of other consumption practices, which are gender neutral, or maledominated, for example gaming, might prove a fruitful context to further our understanding of consumption-based CoP.

The study is also limited to beauty UGC creators; future studies might focus also, or more broadly, on the audiences for beauty UGC. As Fuller (2007) points out CoP can be understood to operate broadly at multiple levels. Similarly, Berryman and Kavka (2017) suggest that it might be possible to conceptualise UGC creators and their audiences as a series of communities within communities, and further research might explore those broader perspectives.

\section{Conclusion}

Beauty UCG creators have become powerful influencers, particularly via YouTube, in beauty brand communications (Pixability, 2015) and are therefore of considerable managerial interest (WARC, 2011). While consumption-based community has been previously theorised in a number of ways, consumption-based CoP has been considered only to a limited extent. Here beauty UGC creators are demonstrated to engage in mutual social connection and support, shared repertoires of UGC creation, and to reference and align their practice with the beauty UGC community. Understanding 
beauty UGC creators as a COP, as creators and learners, linked by their passion and desire to deepen expertise is a key insight for managers who wish to leverage their channels and audiences.

\section{Acknowledgments}

The authors acknowledge the support of Dublin Institute of Technology and University College Dublin in the conduct of this research.

\section{Disclosure statement}

No potential conflict of interest was reported by the authors.

\section{Notes on contributors}

Valerie Gannon is a Lecturer in Advertising at Dublin Institute of Technology. Her research has been published in the European Journal of Marketing and the Journal of Customer Behaviour. +353$1-4023000$.

Andrea Prothero is Professor of Business and Society at the UCD College of Business. She has published widely in the broad Marketing and Society field.

\section{References}

Allen, K., \& Mendick, H. (2013). Keeping it real? Social class, young people and 'authenticity' in reality TV. Sociology, 47(3), 460-476.

Anderson, M. (2015, February 12). 5 facts about online video, for YouTube's 10th birthday. FactTank: News in the Numbers. Washington, DC: Pew Research Center. Retrieved from http:// www.pewresearch.org/fact-tank/2015/02/12/5-facts-about-online-video.

Arsel, Z., \& Bean, J. (2013). Taste regimes and market-mediated practice. Journal of Consumer Research, 39(5), 899-917.

Arsel, Z., \& Zhao, X. (2013). Blogs. In R. W. Belk \& R. Llamas (Eds.), The Routledge companion to digital consumption (pp. 53-61). New York: Routledge.

Aslama, M., \& Pantti, M. (2006). Talking alone: Reality TV, emotions and authenticity. European Journal of Cultural Studies, 9(2), 167-184.

Bakardjieva, M. (2003). Virtual togetherness: An everyday life perspective. Media Culture \& Society, 25(3), 291-313.

Ballve, M. (2015, March 20). YouTube seems to be slipping, but it's actually well positioned to take on the rise of Facebook, vine, and Snapchat. Business Insider. Retrieved from http://uk.busines sinsider.com/youtube-and-the-future-of-online-video-2015-3? r=USIR=T.

Berryman, R., \& Kavka, M. (2017). 'I guess a lot of people see me as a big sister or a friend': The role of intimacy in the celebrification of beauty vloggers. Journal of Gender Studies, 26(3), 307-320.

Biressi, A., \& Nunn, H. (2012). Reality TV: Realism and revelation (2nd ed.). New York: Columbia University Press.

Blanchard, A. (2004). Blogs as virtual communities: Identifying a sense of community in the Julie/ Julia Project, University of Minnesota. The University of Minnesota Digital Conservancy. Retrieved from http://hdl.handle.net/11299/172837.

Blanchard, A., Askay, D. A., \& Frear, K. (2010). Sense of community in professional virtual communities. In S. D. Long (Ed), Communication, relationships and practices in virtual work (pp. 161177). New York: Hershey. 
boyd (sic), D. (2006). A blogger's blog: Exploring the definition of a medium. Reconstruction: Studies in Contemporary Culture, 6(4). Retrieved from http://reconstruction.eserver.org/lssues/064/boyd. shtml

Burgess, J. (2007). Blogging to learn, learning to blog. In A. Bruns \& J. Jacobs (Eds.), Uses of Blogs. New York: Peter Lang Publishing.

Burgess, J., \& Green, J. (2009). Online video and participatory culture. Cambridge: Polity Press.

Canniford, R. (2011a). A typology of consumption communities. In R. W. Belk, K. Grayson, A. M. Muñiz, \& H. J. Schau (Eds.), Research in consumer behavior 13 (pp. 57-75). Bingley: Emerald Group Publishing.

Canniford, R. (2011b). How to manage consumer tribes. Journal of Strategic Marketing, 19(7), 591-606.

Cova, B., \& Cova, V. (2002). Tribal marketing: The tribalisation of society and its impact on the conduct of marketing. European Journal of Marketing, 36(5/6), 595-620.

Cova, B., Kozinets, R., \& Shankar, A. (2007). Consumer tribes. Oxford: Butterworth-Heinemann.

Dennen, V. P. (2014). Becoming a blogger: Trajectories, norms, and activities in a community of practice. Computers in Human Behavior, 36, 350-358.

Dolbec, P.-Y., \& Fischer, E. (2015). Refashioning a field? Connected consumers and institutional dynamics in markets. Journal of Consumer Research, 41(6), 1447-1468.

Downes, S. (2007). Learning networks in practice. Emerging Technologies for Learning, 2. Coventry: BECTA.

Droge, C., Stanko, M. A., \& Pollitte, W. A. (2010). Lead users and early adopters on the web: The role of new technology product blogs. Journal of Product Innovation Management, 27(1), 66-82.

The Economist. (2015, December 3). Male grooming in South Korea: The east is rouge - How local cosmetics brands are getting under men's skin. Retrieved from http://www.economist.com/ news/business/21679459-how-local-cosmetics-brands-are-getting-under-mens-skin-east-rouge.

Edwards, S. M. (2011). A social media mindset. Journal of Interactive Advertising, 12(1), 1-3.

Fader, P. S., \& Winer, R. S. (2012). Introduction to the special issue on the emergence and impact of user-generated content. Marketing Science, 31(3), 369-371.

Feifer, J. (2015, July 22). Is this a Selfie? The New York Times, Opinion Pages. Retrieved July 22 from http://www.nytimes.com/2015/07/22/opinion/is-this-a-selfie.html.

Fuller, A. (2007). Critiquing theories of learning and communities of practice. In J. Hughes, N. Jewson \& L. Unwin (Eds), Communities of practice: critical perspectives (pp. 17-30). Abingdon: Routledge.

Goulding, C., Shankar, A., \& Canniford, R. (2013). Learning to be tribal: Facilitating the formation of consumer tribes. European Journal of Marketing, 47(5), 813-832.

Goulding, C., Shankar, A., \& Elliott, R. (2002). Working weeks, rave weekends: identity fragmentation and the emergence of new communities. Consumption, Marketing \& Culture, 5(4), 261-284.

Gunawardena, C. N., Hermans, M. B., Sanchez, D., Richmond, C., Bohley, M., \& Tuttle, R. (2009). A theoretical framework for building online communities of practice with social networking tools. Educational Media International, 46(1), 3-16.

Hall, V. (2017, January 12). As MAC unveils its first ever beauty influencers collection, here are the social media stars you should be following. The Telegraph. Retrieved from http://www.telegraph. co.uk/beauty/people/best-beauty-influencers-have-radar/.

Harnish, R. J., \& Bridges, K. R. (2016). Mall Haul videos: Self-presentational motives and the role of self-monitoring. Psychology and Marketing, 33(2), 113-124.

Hartmann, B. J., Wiertz, C., \& Arnould, E. J. (2015). Exploring consumptive moments of valuecreating practice in online community. Psychology and Marketing, 32(3), 319-340.

Hess, A. (2016, October 18). Those Lips! Those eyes! That stubble! The transformative power of men in makeup. The New York Times, Art \& Design: Critics Notebook. Retrieved October 18 from http://www.nytimes.com/2016/10/19/arts/design/those-lips-those-eyes-that-stubble-the-trans formative-power-of-men-in-makeup.html?mwrsm=Email\&_r=0.

Hughes, J., Jewson, N., \& Unwin, L. (2007). Introduction. communities of practice: a contested concept in flux. In J. Hughes, N. Jewson \& L. Unwin (Eds.), Communities of practice: Critical perspectives (pp. 17-30). Abingdon: Routledge 
Jeffries, L. (2011). The revolution will be soo cute: YouTube "Hauls" and the voice of young female consumers. Studies in Popular Culture, 33(2), 59-75.

Johnson, L. (2015, April 27). How brands and YouTube channels are hooking up to reach millions of millenials: 5 case studies in marketing with original video content. Adweek. Retrieved from http://www.adweek.com/news-gallery/technology/how-brands-and-youtube-stars-are-hookingreach-millions-millennials-164316.

Jones, Q. (1997). Virtual-communities, virtual settlements \& cyber-archaeology: A theoretical outline. Journal of Computer-Mediated Communication, 3(3). doi:10.1111/j.1083-6101.1997.tb00075.x

Kollock, P., \& Smith, M. A. (1999). Communities in cyberspace. In M. A. Smith \& P. Kollock (Eds.), Communities in cyberspace (pp. 3-29). London: Routledge.

Kozinets, R. (2010). Netnography: Doing ethnographic research online. London: Sage.

Kozinets, R. V. (1999). E-tribalized marketing? The strategic implications of virtual communities of consumption. European Management Journal, 17(3), 252-264.

Kozinets, R. V., de Valck, K., Wojnicki, A. C., \& Wilner, S. J. S. (2010). Networked narratives: Understanding word-of-mouth marketing in online communities. Journal of Marketing, 74(2), 71-89.

Kretz, G. (2012). Consuming branded stories: A netnography of fashion and luxury blog consumption. Advances in Consumer Research, 40, 1057-1058.

Kretz, G., \& de Valck, K. (2013). Fashion bloggers. In R. W. Belk \& R. Llamas (Eds.), The digital consumer (pp. 62-71). London: Routledge.

Lange, P. (2009). Videos of affinity on YouTube. In P. A. Snickars \& P. Vonderau (Eds.), The YouTube reader (pp. 70-88). Stockholm: National Library of Sweden.

Lave, J., \& Wenger, E. (1991). Situated learning: Legitimate peripheral participation. Cambridge: Cambridge University Press.

Lehmuskallio, A., \& Cruz, E. G. (2016). Why material visual practices? In E. G. Cruz \& A. Lehmuskallio (Eds.), Digital photography and everyday life: Empirical studies on material visual practices (pp. 116). Oxford: Routledge.

Light, B., Griffiths, M., \& Lincoln, S. (2012). Connect and create: Young people, YouTube and graffiti communities. Continuum: Journal of Media \& Cultural Studies, 26(3), 343-355.

Lindgren, S. (2012). "It took me about half an hour, but I did it!" Media circuits and affinity spaces around how-to videos on YouTube. European Journal of Communication, 27(2), 152-170.

Lingel, J., \& Naaman, M. (2012). 'You should have been there, man': Live music, DIY content and online communities. New Media and Society, 14(2), 332-349.

McMillan, D. W., \& Chavis, D. M. (1986). Sense of community: A definition and theory. Journal of Community Psychology, 14(1), 6-23.

McQuarrie, E. F., Miller, J., \& Phillips, B. J. (2013). The megaphone effect: Taste and audience in fashion. Journal of Consumer Research, 40(1), 136-158.

Miles, M. B., Huberman, M. A., \& Saldaña, J. (2014). Drawing and verifying conclusions: Qualitative data analysis: A methods sourcebook. Los Angeles: Sage.

Miller, C.R., \& Shepherd, D. (2004). Blogging as social action: A genre analysis of the weblog. In Gurak, L., Antonijevic, S., Johnson, L.A., Ratliff, C. \& Reyman, J. (Eds), Into the blogosphere: rhetoric, community and culture of weblogs. University of Minnesota.

Molyneaux, H., Gibson, K., O'Donnell, S., \& Singer, J. (2008). New visual media and gender: A content, visual and audience analysis of YouTube vlogs. Proceedings of the international communication association annual conference, May.

Morris, M., \& Anderson, E. (2015). Charlie is so cool like: Authenticity, popularity and inclusive masculinity on YouTube. Sociology, 49(6), 1200-1217.

Muñiz, M. A., Jr, \& O'Guinn, T. C. (2001). Brand community. Journal of Consumer Research, 27(4), 412-432.

Nicolini, D. (2012). Practice theory, work and organisation: An introduction. Oxford: Oxford University Press.

Patton, M. Q. (2015). Qualitative research \& evaluation methods (4th ed.). Thousand Oaks: Sage.

Pixability (2015). Beauty on YouTube 2015: How YouTube is radically transforming the beauty industry and what that means for brands. Retrieved from http://www.pixability.com/industrystudies/new-beauty/. 
Porter, C. E. (2004). A typology of virtual communities: A multi-disciplinary foundation for future research. Journal of Computer-Mediated Communication, 10(1). doi:10.1111/j.1083-6101.2004. tb00228.x

Rheingold, H. (1993). The virtual community: Homesteading on the electronic frontier. Massachusetts: Addison Wesley.

Richards, L. (2014). Handling qualitative data: a practical guide. London: Sage Publications.

Rose, G. (2016). Visual methodologies: An introduction to researching with visual materials (4th ed.). London: Sage Publications.

Safronova, V. (2016, October 12). Meet coverGirl's new cover boy. The New York Times, Fashion \& Style, Retrieved October 12. from http://www.nytimes.com/2016/10/16/fashion/meet-covergirlsnew-cover-boy.html?mwrsm=Email.

Saldaña, J. (2011). Fundamentals of qualitative research. Oxford: Oxford University Press.

Schatzki, T. (2012). A primer on practices: Theory and research. In J. Higgs, R. Barnett, S. Billett, \& M. Hutchings (Eds.), Practice-based education: Perspectives and strategies (pp. 13-26). Rotterdam: Sense Publishers.

Schau, H. J., Muñiz, A. M., Jr, \& Arnould, E. J. (2009). How brand community practices create value. Journal of Marketing, 73(5), 30-51.

Schmidt, J. (2007). Blogging practices: An analytical framework. Journal of Computer-Mediated Communication, 12(4), 1409-1427.

Schouten, J. W., \& McAlexander, J. H. (1995). Subcultures of consumption: an ethnography of the new bikers. Journal Of Consumer Research, 22(1), 43-61. doi:10.1086/jcr.1995.22.issue-1

Shapiro, B. (2017, March 20). Is Huda Kattan the most influential beauty blogger in the world? The New York Times, Fashion \& Style.

Shove, E., \& Pantzar, M. (2005). Consumers, producers and practices: Understanding the invention and reinvention of Nordic Walking. Journal of Consumer Culture, 5(1), 43-64.

Shove, E., Pantzar, M., \& Watson, M. (2012). The dynamics of social practice: Everyday life and how it changes. London: Sage.

Silverman, D. (2011). Interpreting qualitative data. London: Sage.

Simonsen, T. M. (2013). The mashups of YouTube. Nordicom Review, 34(2), 47-63.

Sorensen, K., \& Mara, A. (2014). BookTubers as a networked knowledge community. In M. Limbu \& B. Gurung (Eds.), Emerging pedagogies in the networked knowledge society: Practices integrating global media and society. Hershey: Information Science Reference.

Spiggle, S. (1994). Analysis and Interpretation of qualitative data in consumer research. Journal of Consumer Research, 21(3), 491-503.

Strugatz, R. (2014, March 14). Vloggers winning online battle over brands. Womens' Wear Daily. Retrieved from http://wwd.com/globe-news/media-features/vloggers-winning-online-battleover-brands-7592082/.

Thomas, T. C., Price, L. L., \& Schau, H. J. (2013). When differences unite: Resource dependence in heterogeneous consumption communities. Journal of Consumer Research, 39(5), 1010-1033.

Tolson, A. (2010). A new authenticity? Communicative practices on YouTube. Critical Discourse Studies, 7(4), 277-289.

Uzunoğlu, E., \& Kip, S. M. (2014). Brand communication through digital influencers: Leveraging blogger engagement. International Journal of Information Management, 34(5), 592-602.

Waldron, J. (2011). Locating narratives in postmodern spaces: A cyber ethnographic field study of informal music learning in online community. Action, Criticism \& Theory for Music Education, 10(2), 32-60.

Waldron, J. (2013). YouTube, fanvids, forums, vlogs and blogs: Informal music learning in convergent onand offline music community. International Journal of Music Education, 31(1), 91-105.

Walker Rettberg, J. (2008). Blogging. Cambridge: Polity.

Walker Rettberg, J. (2014). Seeing ourselves through technology: How we use selfies, blogs and wearable devices to see and shape ourselves. Basingstoke: Palgrave Macmillan.

WARC (2011, January 17). "Mommy Bloggers" boost brands. Retrieved from http://www.warc.com/ LatestNews/News/\%22Mommy_bloggers\%22_boost_brands.news?ID=27770. 
Warde, A. (2014). After taste: Consumption, culture and theories of practice. Journal of Consumer Culture, 14(3), 279-303.

Weinsweg, D. (2017, May 15). How social media influencers helped turn NYX and Becca into multimillion-dollar cosmetics brands. Forbes. Retrieved from https://www.forbes.com/sites/ deborahweinswig/2017/05/15/how-social-media-influencers-helped-turn-nyx-and-becca-intomultimillion-dollar-cosmetics-brands/\#54ecdf307a44.

Wellman, B., Boase, J., \& Chen, W. (2002). The networked nature of community: Online and offline. IT \& Society, $1(1), 151-165$.

Wenger, E. (1998). Communities of practice: Learning, meaning and identities. Cambridge: Cambridge University Press.

Wenger, E. (2000). Communities of practice and social learning systems. Organization, 7(2), 225-246.

Wenger, E. (2010). Communities of practice and social learning systems: The career of a concept. In C. Blackmore (Ed.), Social learning systems and communities of practice. London: Springer.

Wenger, E., McDermott, R., \& Snyder, W. M. (2002). A guide to managing knowledge: Cultivating communities of practice. Boston: Harvard Business School.

Woermann, N. (2012). On the slope is on the screen: prosumption, social media practices, and scopic systems, in the freesking subculture. American Behavioural Scientist, 56(4), 618-640. 